\title{
Examining Trends in Chinese Secondary Education: From Test-Oriented to Comprehensive Academic and Personal Student Development
}

\author{
Yang Fan, Chen Cheng \\ University of the Pacific, California, USA
}

\begin{abstract}
With the development of Chinese education, voices of encouragement and criticism both exist in the field of educational research. The College Entrance Examination (CEE) has been identified as one of the causes of several contested issues in Chinese education. Reforms to the CEE have been implemented to address different issues in Chinese education. Hengshui High School (HHS) is a well-known high school in China, which boasts high college admission rates. The researchers explored the policies and practices of HHS to understand its methods for cultivating students. This article aims to examine the trends of Chinese secondary education reflected in the reform of the CEE in China and HHS's shift from test-oriented practices to a focus on comprehensive academic and personal development of students. This article will provide background information about the CEE and HHS, and also, it will discuss the trends and changes in the CEE and in HHS. This article argues that Chinese education is transforming from a test-orientation to a focus on comprehensive student development. However, this trend has not yet spread widely throughout China. Recommendations for further research are also provided.
\end{abstract}

Keywords: Chinese secondary education, College Entrance Examination (CEE), Hengshui High School (HHS), trends and changes in Chinese secondary education

\section{Introduction}

In the summer of 2017, over 9.4 million Chinese high school students participated in the College Entrance Examination (CEE) in China (Chinese Education Online, 2017). Although the average college admission rate in 2016 throughout China was 82.15\%, only 15.86\% students who took the CEE in Hebei Province went to tier-one universities. The admission rate for students in Hebei Province who went to prestigious universities, namely, the "985" and "211" universities, was $1.48 \%$ and $4.42 \%$, respectively (Chinese Education Online, 2016). Although the requirements to go to prestigious and tier-one universities are competitive, there is a high school, namely, Hengshui High School (HHS) in Hebei Province which has achieved the distinction of having an impressive number of students gain admittance into tier-one and prestigious universities since 2001 (Wang Yi \& Wang Yue, 2015). In 2017, 18 Hebei Province students who studied science subjects earned over 700 (out of 750) in the CEE, and 11 of the students were from HHS (Wang, 2017). In addition, according to the China 500 High Schools Academic Competition Ranking List published in 2017 (Academic Competition Website,

Yang Fan, M.A./Ed.D. student, School of Education, University of the Pacific.

Chen Cheng, M.A./Ed.D. student, School of Education, University of the Pacific. 
2017), HHS ranked first among the 500 top high schools in China. The ranking shows that HHS not only holds the dominate ranking among high schools in Hebei Province, but also takes the lead among Chinese high schools.

However, despite the impressive achievement of its students, HHS is not universally praised (Wang Yi \& Wang Yue, 2015; Xiong, 2012; Ye, 2015). Some mainstream media and educators criticize HHS as a "CEE boot camp" or "CEE machine factory." They believe that although HHS meets the demands of the current Chinese secondary educational system and the CEE, the achievements are at the expense of students' creativity, critical thinking ability, and intellectual curiosity (Wang Yi \& Wang Yue, 2015). Moreover, in 2014, a CEE reform took place in the evaluation system and subject design (Bian, 2015; Yang, 2015; Chen \& Ye, 2015). Under the new reform, the CEE score is no longer the only criteria for deciding students' admission to college. Instead, the comprehensive academic and personal development of students are considered important components in the CEE evaluation system (Bian, 2015; Yang, 2015; Chen \& Ye, 2015). The CEE reform reflects the trend in Chinese secondary education away from standardized testing toward comprehensive student development. The reform poses challenges to the trends and practices of HHS, which is a representative high school model in Chinese secondary education.

This article aims to examine the trends in Chinese secondary education reflected by HHS and the reform of the CEE in China from test-oriented to students' comprehensive academic and personal development. In the first section, we will provide an overview of the CEE in China, including its function, problems, and recent reforms. Then, an introduction to HHS students' management, instructional strategies, and teacher management is given. The third section explores the trends in Chinese secondary education reflected by HHS and the CEE's shift from test-oriented to comprehensive student development. The last section of the article includes recommendations for further studies.

\section{The College Entrance Examination in China}

\section{Introduction to the College Entrance Examination}

In China, the CEE, also called "gaokao," is a Nationwide Educational Standardized Test whose purpose is to recruit qualified high school students for colleges and universities (Feng, 1999; Zhou, 2009). The CEE has been hotly debated by educators and researchers because of its significant functions in Chinese educational (Zhou, 2009; Zheng, 2005, 2007b), cultural (Zheng, 2007b; Shangguan, 2009; Jiang, 2007), social (Zheng, 2007a; Zhou, 2009; Shangguan, 2009; Li \& Zheng, 2008; Liu, 2005), and political and economic (Zheng, 2007b; Jiang, 2007) development. Specifically, in its educational function, the CEE is viewed as a guide for kindergarten to Grade 12 (K-12) education (Sun, 2009; Zheng, 2007b; Zhou, 2009) and as a bridge between K-12 and higher education (Sun, 2009). Sun (2009) pointed out that the binary effect of the CEE on Chinese secondary education. The CEE could positively lead secondary education towards being more scientific and efficient, however, if inappropriately implemented, the CEE could negatively influence Chinese secondary education and student academic and personal development (Sun, 2009).

\section{Issues With the College Entrance Examination}

To some extent, the CEE has been the only benchmark for assessing educational outcomes in K-12 education, especially in secondary education (Zheng, 2007a). Zheng and Wan (2015) critically evaluated the CEE system and claimed that it is problematic that colleges and universities lack the rights for autonomic enrollment. 
Research also criticized the CEE for limiting secondary education and fueling the phenomenon of high schools excessively pursuing impressive college admission rates. In fact, it is often the case that the knowledge tested by the CEE is in accordance with the content taught by secondary teachers and learned by high school students in order to achieve better scores and higher college admission rates. (Zheng, 2005, 2007a, 2007b; Zheng \& Wan, 2015)

However, in this case, secondary education fails to prepare high school students with a comprehensive knowledge background for their holistic development (Zheng, 2005). Likewise, Sun (1999) and Zheng (2007b) claimed that under the charge of the CEE, secondary education ignores students' personality, constrains their creativity, and decreases their motivation to learn.

With the purpose of addressing the critical issues of the CEE mentioned above, researchers advocated to the CEE reform in order to provide high school students with comprehensive academic and personal development (Liao, 2002; Sun, 2009; Duan, 2010; Jiang, 2015). Liao (2002) and Sun (2009) proposed that educational evaluation should emphasize students' comprehensive abilities. Liao (2002) also suggested that high school students should be given more freedom to choose what subjects to be tested on besides the compulsory examination subjects (i.e., Chinese literacy, mathematics, and English literacy). Similar changes were announced in the 2014 CEE reform, which took place in Shanghai and Zhejiang provinces (Chen \& Ye, 2015; Bian, 2015). The new research-based reform aims to acknowledge the importance of developing students' comprehensive abilities in secondary education and deter Chinese education from paying too much attention on test scores and college admission rates (Bian, 2015; Yang, 2015; Chen \& Ye, 2015).

Actions in the 2014 CEE reform took place mostly in the evaluation system and subject design (Bian, 2015; Yang, 2015; Chen \& Ye, 2015). In regard to the evaluation system, according to the new reform, the CEE score is no longer considered the only evaluation criteria for college admission. Instead, two additional criteria were added: academic test for the ordinary high school students (ATOHS) and comprehensive quality assessment information of high school students (CQAIHS) (Bian, 2015; Yang, 2015; Chen \& Ye, 2015). ATOHS is the test organized by the provincial education administration to evaluate student academic achievement in secondary education. This test evaluates students' performance in each subject area in secondary education (Ministry of Education of the People's Republic of China [PRC], 2014). CQAIHS is the evaluation of a student's comprehensive abilities, including moral character, physical fitness, practical ability, and sense of social responsibility (Yang, 2015). To be more specific, scores for the CEE and ATOHS is the core of evaluation criteria for college admission, but the comprehensive quality assessment information of individual students should be also taken into account by colleges and universities as a requirement. Researchers praised this action, because it would effectively discourage secondary education from over-emphasizing exam scores (Chen \& Ye, 2015) and would be beneficial for promoting comprehensive academic and personal student development (Bian, 2015; Yang, 2015).

In regard to subject design, the new reform abandoned the systemic division of liberal arts and science in secondary education (Yang, 2015; Bian 2015). The division of liberal arts and science is a way to separate liberal arts subjects and science subjects. Except for Chinese, English, Mathematics, and minor subjects (e.g., Music and Physics Education [PE]), History, Politics, and Geometry are considered components of liberal arts, while Physics, Chemistry, and Biology are included in science subjects. Zhu (2004) pointed out that,

In most cases, because of the difficult nature of science subjects in Chinese secondary education, those students who prefer liberal arts usually have poor performance in science subjects. Therefore, the systemic division of liberal arts and science led to weakened liberal education in China, and it also led to an unbalance in student knowledge. For instance, 
those who choose science subjects overlook liberal arts learning, or even give up.

In addition, the new reform intended to generalize a new model of subject design for the CEE, called the “ $3+3$ ” model. The first " 3 " stands for the three compulsory examination subjects (i.e., Chinese, English, and Mathematics) and the second " 3 " refers to the three elective subjects chosen by students from Physics, Chemistry, Biology, History, Politics, and Geometry (Yang, 2015; Bian, 2015). In other words, for now, the CEE score contains six subject test scores, half of which are compulsory subject tests scores and the other half are elective subject test scores. In the replacement of the " $3+3$ ” model, students are not prematurely forced to major in liberal arts or science, instead, they are required to learn all subjects, but also have the freedom to choose the subjects in which they have interest and/or talent (Yang, 2015; Bian, 2015).

\section{The Hengshui High School}

\section{Introduction to Hengshui High School}

The HHS is located in Hengshui, a city in mid-eastern China, which has the population of 4.32 million based on the 2013 census (Hengshui Census Bureau, 2011). The city is in southern Hebei Province, an economically disadvantaged area in China (Yang, Tang, Zhang, \& Dong, 2006). HHS was established in 1951 and was one of the first demonstrative high schools in Hebei Province (Zhang, 2016). According to the data from 2014, the school has around 8,000 students on campus from Grades 10-12, with around 600 faculty members (The 360 Encyclopedia, 2013). From 2001 to 2014, HHS continuously ranked first for the college entrance rate in Hebei Province (Wang Yi \& Wang Yue, 2015). For example, in 2014, 86.6\% of students who graduated from HHS went to tier-one universities in China, while the average acceptance rate for Hebei Province students into tier-one universities was 10.23\% (Wang Yi \& Wang Yue, 2015). In addition, HHS has the largest number of students who were admitted to Peking University and Tsinghua University, the two most prestigious universities in China (Wang Yi \& Wang Yue, 2015; Yang, Tang, Zhang, \& Dong, 2006).

In recent years, the high performance of HHS students in the CEE has captured the attention of researchers, educational practitioners, parents, and students. Many researchers have investigated the student management, instructional strategies, and teacher management of HHS. For following sections, we will discuss HHS from the aspects of student management, instructional strategies, and teacher management to provide an overview of ways in which HHS meets the trends of the Chinese secondary education system and the CEE.

\section{Student Management}

HHS stresses the importance of quantitative time management in organizing students' time on campus (Wang Yi \& Wang Yue, 2015; Xiong, 2012). From 5:30 in the morning when students get up until 10:00 at night when students go to bed, every minute is specifically managed by the school schedule (Wang Yi \& Wang Yue, 2015). In order to focus students' attention on studying and avoid outside distractions, HHS adopts the military model of sealed management by having students' eat, live, and study every day at the school except for holidays and regular one-day breaks every two or three weeks (Tian, Wang, \& Jiang, 2016; Wang Yi \& Wang Yue, 2015). Students are not allowed to use phones or the Internet on campus, and girls and boys are not allowed to interact closely to prevent students from getting distracted from their studies (Wang Yi \& Wang Yue, 2015).

Self-motivation is an important method for inspiring students to study hard at HHS (Wang Yi \& Wang Yue, 2015). The current principal of HHS, Wenmao Zhang, proposed the idea of making school a "mind and spirit special zone,” an attempt to intentionally align students' mindset with the purpose of education according 
to the dominate value of society (Yang, Tang, Zhang, \& Dong, 2006; Ye, 2015; Zhang, 2016). Shouting slogans during the morning exercises and posting posters in the classrooms are traditions in HHS to remind students to reflect on "What is the purpose of studying at the school today? What kind of person do I want to be? And how am I achieving my purpose today?” (Wang Yi \& Wang Yue, 2015, p. 9).

While HHS employs a militaristic daily routine to facilitate rigorous academics, the school also pays attention to the moral and character education of students. Special events are held throughout the school year to target student development. These events include adult ceremonies, long distance hiking trips, theatre productions, selection of moral role models, and so on (Zhang, 2016). HHS has more than 50 student clubs to cultivate students' specialties, such as a traditional Chinese culture study group, folk music club, and handcrafts club, etc. (Zhang, 2016). HHS also developed over 100 school-based curricula to diversify students' individual development and interests with topics related to technology, life education, and many other aspects (Ye, 2015; Zhang, 2016).

\section{Instructional Strategies}

HHS's philosophy of "making teaching an art" means teachers act as facilitators of student learning rather than traditional dominant operators of the classroom (Li, 2016; Yang, Tang, Zhang, \& Dong, 2006; Zhang, 2016). The school utilizes a "two five-minute" policy: A teacher's lecture cannot last over five minutes without students participating in the class discussion or answering questions at least once and the last five minutes of the class must be left for students to reflect and summarize the lesson (Wang, Zhang, \& Han, 2006).

Different from the traditional way of assigning large amounts of homework and exercises to students, the principal requires teachers to change their focus from mechanical drills to improve students' speed to specific exercises designed to refine students' understanding of key and difficult points of the material (Wang, Zhang, \& Han, 2006; Yang, Tang, Zhang, \& Dong, 2006). The school divides the student self-study time into two parts: individual study of one subject assigned by a subject teacher to be completed within a limited amount of time as well as individual study of student-selected subjects and assignments (Wang, Zhang, \& Han, 2006; Yang, Tang, Zhang, \& Dong, 2006; Zhang, 2016). The self-study time ensures students' learning time management skills. Meanwhile, the school forbids any teachers from commandeering individual study time to teach class material (Yang, Tang, Zhang, \& Dong, 2006). The school requires the students to treat every self-study time like taking a test and regard taking every test as if it is the CEE (Wang, Zhang, \& Han, 2006).

\section{Teacher Management}

Jinchi Li, former principal of HHS from 1992 to 2004 and the superintendent of Hengshui city from 2004 to 2010, implemented the function formula " $y=k x$ " to represent the relationship between student performance and teachers' cultivated personality and teaching capacity (Yang, Tang, Zhang, \& Dong, 2006). Li believes that when a teacher's cultivated personality " $k$ " is maximized positively, that teacher's capacity for teaching " $x$ " leads to positive results in student performance " $y$." However, when the teacher's cultivated personality " $k$ " is negative or zero, students will not like their teachers, leading to negative or low student performance (Yang, Tang, Zhang, \& Dong, 2006). In order to maximize teachers' cultivated personality and set up positive models for students, Li sets up school rules that forbid teachers from receiving gifts or dining with students and students' parents. In addition, teachers who teach at HHS are not allowed to hold paid remedial classes for students during holidays or on weekends. Teachers' salaries are not largely dependent on class evaluations and 
teachers are not allowed to smoke, play mahjong, or dress unprofessionally on campus (Yang, Tang, Zhang, \& Dong, 2006; Zhang, 2016).

Leaders at HHS aim to transform teachers' motivation from teaching as an occupation to teaching as a career. Novice teachers hired by HHS need to pass five assessments related to morality, instructional strategies, pedagogies, educational management, and the ability to conduct educational research. Only after passing all five assessments will teachers become qualified and official teachers at HHS (Yang, Tang, Zhang, \& Dong, 2006).

\section{From Test-Oriented to Comprehensive Student Development}

\section{Test-Orientation at Hengshui High School}

The outstanding performance of HHS students on the CEE and high admission rates to tier-one and prestigious universities is the outcome of rigorous student management policies. Since the current CEE system encourages secondary education to be scientific and efficient (Sun, 2009), quantitative time management is used for regulating students' schedules on campus (Wang Yi \& Wang Yue, 2015; Xiong, 2012). This kind of student management stresses the importance of numbers and time as the criteria for evaluation and assessment. Every minute of school time is regulated to maximize students' study time and energy to prepare for the CEE (Wang Yi \& Wang Yue, 2015).

Moreover, militaristic daily routines and sealed management are applied to forbid students from going outside of school grounds without teachers’ permission (Wang Yi \& Wang Yue, 2015; Xiong, 2012).

Students have very limited breaks during weekends and holidays to avoid any distraction from preparing for the CEE. Since students cannot have access to phones and the internet, their life is essentially restricted to a singular focus on studying test materials. The tight schedule and enormous pressure for preparing for the CEE devalues students' creativity and intellectual curiosity. The rigorous student management policies make some media refer to HHS as a "CEE factory." They believe HHS applies rigorous quantitative time management to enhance efficiency and maximize production of high CEE scores and college admission rates. (Wang Yi \& Wang Yue, 2015)

The instructional strategies at HHS also contribute to high performance for students in the CEE. Since the CEE has been the only benchmark for assessing educational outcomes for secondary education (Zheng, 2007a), and most of the students only have one chance to take it in their lifetime (Zheng \& Wan, 2015), HHS has made every effort to ensure students' perform well on this high-stake test. HHS requires students to look upon every self-study time as if they are taking a test and take every test as if it is the CEE in order to enhance students' efficiency (Wang, Zhang, \& Han, 2006). Moreover, in preparation for the CEE, no matter students' interests and personalities, all the students are required to study Chinese, Mathematics, and English as the three main subjects for the CEE and mainly focus their attention on subjects and study materials related to the CEE. Regardless of students' abilities and levels, they always need to study and be prepared to perform at their best in order to achieve the highest score they can on the CEE (Xiong, 2012).

The teacher management in HHS is also closely related to student performance and achievement (Yang, Tang, Zhang, \& Dong, 2006). The function formula " $y=k x$ ” from the former principal of HHS reflects the school's dedication to improving teachers' character to stimulate student performance on the CEE. A series of measures have also been taken to set up positive teacher models for students (Yang, Tang, Zhang, \& Dong, 2006).

From student management, instructional strategies, and teacher management, test-orientation is still the obvious standard for practice at HHS. The quantitative time management, militaristic daily routines, and sealed 
management are designed to maximize students' study time and academic potential, while rigorous management policies are implemented to avoid students' distraction from studying for the CEE (Wang Yi \& Wang Yue, 2015; Wang, Zhang, \& Han, 2006; Xiong, 2012; Yang, Tang, Zhang, \& Dong, 2006). Given that HHS in Hebei Province is an economically disadvantaged area in China, many students from low socio-economic status families and rural areas look upon the CEE as the only route to achieve social mobility, which greatly intensifies pressure on students to study for the high-stake test (Ke, 2012; Wang Yi \& Wang Yue, 2015; Xiong, 2012; Ye, 2015). However, with the development of secondary education and changes in the CEE, HHS is also in the process of shifting from teaching to the test to cultivating comprehensive student development.

\section{Comprehensive Student Development in Hengshui High School}

Besides emphasizing students' test scores, HHS takes several actions for supporting comprehensive student development. As mentioned above, aspects of comprehensive academic and personal development of students include moral character, physical fitness, practical ability, and sense of social responsibility (Liao, 2002; Sun, 2009). Also, according to the 2014 reform, Chinese education tried to relieve the heavy stress on students to pass the CEE (Bian, 2015). As mentioned above, students are encouraged to perform well in their daily learning, because ATOHS and CQAIHS scores are now also viewed as criteria and references for college admission (Bian, 2015; Yang, 2015; Chen \& Ye, 2015). In addition, students have more freedom to choose what to be tested on during the CEE besides Chinese, English, and Mathematics. In one word, the 2014 CEE reform aims to redirect Chinese education from paying too much attention on test scores and college admission rates, and instead dedicate time and resources to improving comprehensive student development (Bian, 2015; Yang, 2015; Chen \& Ye, 2015).

HHS mainly puts effort into improving different aspects of student academic and personal development. Zhang (2016) mentioned that HHS selects moral models for students. In other words, the school holds an election to choose students with outstanding moral character to become the role models for other students. Having moral models for students is meant to develop students' moral character in a positive way. Also, HHS usually holds a coming-of-age ceremony for senior students who are 18-year-old, which is the traditional age of adulthood in Chinese culture (Zhang, 2016). The coming-of-age ceremony is important for students, because it conveys the sense of becoming an adult and the awareness of taking more personal and social responsibilities (Yao \& Du, 2010). There is no doubt that HHS supports developing students' moral character and social responsibilities via the coming-of-age ceremony. In addition, one of the traditions in HHS is to remind students what the purpose of learning is, what kind of person they want to be, and how to achieve their personal goals by shouting aloud during morning exercises and posting posters in classroom buildings (Wang Yi \& Wang Yue, 2015). This is a way to enhance every student's commitment to be a responsible student and a productive citizen. Moreover, HHS requires students to participate in morning set-up exercises (Wang Yi \& Wang Yue, 2015) and long-distance hiking trips (Zhang, 2016). These activities provide students the chance to take part in physical exercises to become stronger and healthier, and to some extent, to get relief from the heavy academic load. Furthermore, more than 50 student clubs in HHS are designed to cultivate students' interests and the list of clubs include a traditional Chinese culture study group, a folk music club, handcraft club, etc. (Zhang, 2016). Students are encouraged to discover and foster different interests, to learn to manage their own clubs, and to use their knowledge practically into contributing to both the clubs and the school. 
In conclusion, on one hand, HHS puts great emphasis on scores and college admission rates, and on the other hand, acts to improve comprehensive student development. It must be noted that the purpose of the 2014 CEE reform is not fully embodied in HHS. One possible reason is that the 2014 CEE reform took place only in Shanghai and Zhejiang provinces, which have very little impact, for now, on Hebei Province where HHS is located. Therefore, in Hebei Province, almost nothing has been changed in the evaluation system and the CEE's subject design. In other words, a student's score on the CEE is still the only benchmark for college admission, and schools are still driven to compete for high college admission rates. In addition, research on the effectiveness of HHS's practices for supporting comprehensive student development is limited. Therefore, exactly how these practices work to improve and support comprehensive and personal development remains unknown.

\section{Conclusions}

The purpose of this article is to examine the trends and changes in Chinese secondary education by exploring the examples set by the reformed CEE and HHS. It can be concluded that Chinese secondary education is in the process of transforming from test-oriented to a focus on comprehensive student development. Educational research on the CEE and the 2014 CEE reform both indicate the importance of caring more about comprehensive academic and personal development. In the meantime, HHS is an example of a school that provides multiple types of support for its students to improve both academically and holistically. However, it is important to note that the intended results of the 2014 CEE reform have not yet spread nationwide. In other words, with the exception of Shanghai and Zhejiang provinces, Chinese secondary education, especially in Hebei Province where HHS is located, still puts great emphasis on scores and college admission rates. Therefore, although Chinese secondary education has started to emphasize the comprehensive academic and personal development of students, it has not yet fully moved away from the test-oriented approach. In addition, research on the effectiveness of HHS's practices for supporting comprehensive student development is limited. Further research is recommended to explore the following issues:

1. How these policies and practices impact student academic achievement and personal development?

2. What the real outcomes of these practices?

3. How students perceive these practices in order to better understand the trends and changes in Chinese secondary education?

\section{References}

Academic Competition Website. (2017). China 500 high schools academic competition ranking list. Retrieved November 28, 2017, from http://www.sohu.com/a/198573215_228615

Bian, X. (2015). The influence of the new reform of the college entrance examination on secondary education and corresponding countermeasures. Journal of the Chinese Society of Education, 30(7), 16-21.

Chen, F., \& Ye, Z. (2015). A new reform of the college entrance examination: To create an environment for improving student comprehensive development. Modern Teaching, 31(15), 5-8.

Chinese Education Online. (2016, June). Report on college enrollment in China. Retrieved November 27, 2017, from http://www.360doc.com/content/16/0612/17/13005549_567185188.shtml

Chinese Education Online. (2017, August). Report on college enrollment in China. Retrieved November 27, 2017, from http://gaokao.eol.cn/news/201708/t20170823_1549178.shtml

Duan, J. (2010). College entrance examination reform: Change the symptoms not the disease. Journal of Hubei University of Education, 27(10), 107-109. 
Feng, Y. (1999). National college entrance examinations: The dynamics of political centralism in China's elite education. Journal of Education, 181(1), 39-57.

Hengshui Census Bureau. (2011, May). Bulletin of the Sixth National Population Census of Hengshui: 2010-2011. Retrieved October 30, 2017, from http://www.hstjj.gov.cn/pczl/2012/07/17/content_239759.shtml

Jiang, C. (2007). Theory on abolition of the College Entrance Examination: A beautiful mandala. Higher Education Research and Evaluation, 2(6), 62-64.

Jiang, G. (2015). Adhere to strengthening moral education and cultivating people as the core, and to deepen the reform of the content of the College Entrance Examination. China Higher Education, 51(Z2), 31-34.

Ke, Z. (2012). Education and students' upward social mobility: An additional remark to the discussion of Hengshui-High-School phenomenon. Studies on Educational Development, 33(6), 23-27.

Li, Q. X. (2016). The revolution of teaching and learning under new curriculum: My thoughts on understanding Hengshui High School educational revolution. Chinese Science, Technology, and Economics News Database, 4(1), 7.

Li, Z., \& Zheng, Y. (2008). Analysis on the weakening function of social stratification in the College Entrance Examination. Educational Review, 24(6), 63-67.

Liao, P. (2002). Deepen the reform of the College Entrance Examination to promote the comprehensive development of people. College and University Admission, 11(5), 24-25.

Liu, H. (2005). Where to go, the College Entrance Examination. Educational Research, 27(3), 29-34.

Ministry of Education of the People's Republic of China (PRC). (2014). Opinions of the Ministry of Education on the implementation of the academic proficiency test in ordinary high schools. Retrieved November 27, 2017, from http://www. moe.edu.cn/moe_879/moe_191/s4559/201412/t20141216_181664.html

Shangguan, Z. (2009). Deep socialization function of the College Entrance Exam. Educational Science Research, 20(1), 15-19.

Sun, H. (2009). Reduce the negative impact of the College Entrance Examination on secondary education. Journal of Teaching and Management, 21(13), 75-77.

The 360 Encyclopedia. (2013, May). Hengshui High School (HHS). Retrieved November 26, 2017, from https://baike.so.com/doc/5393926-5631004.html

Tian, H. Z., Wang, D., \& Jiang, J. H. (2016). An institutional logic analysis of the phenomenon and evolution of super high school: Take Hengshui High School, Mao Tanchang High School, and Huanggang High School as examples. Education and Economics, 32(5), 3-11.

Wang, R. (2017, September). What is the college admission rate of Hengshui High School? Retrieved November 28, 2017, from http://www.ccutu.com/142277.html

Wang Yi, \& Wang Yue. (2015). Hengshui High School educational model worth pondering. Journal of the Chinese Society of Education, 36(5), 8-12.

Wang, J. Y., Zhang, Y., \& Han, C. J. (2006). Improving teaching quality from routine management: The exploration and thoughts on educational management reform from Hengshui High School in Hebei. Elementary and Middle School Administration, 20(7), 9-11.

Xiong, B. Q. (2012). What are the real problems of Hengshui High School model? Curriculum of Primary Education, 20 (6), 76.

Yang, J. (2015). Discussion about the reform of the College Entrance Examination and the tendency of secondary education. Education Exploration, 31(9), 31-33.

Yang, Z. G., Tang, W. B., Zhang, Y., \& Dong, A. M. (2006). Interpretation of an educational mythology—Exploring Hengshui High School in Hebei Province. Primary Education, 29(4), 4-11.

Yao, S. \& Du, X. (2010). The significance of the returning of adult ceremony. Modern Education Science (Middle School Teacher), 4(2), 58-59.

Ye, S. T. (2015). Facts and value-Agreements and disagreements on Hengshui High School. Journal of the Chinese Society of Education, 39(5), 1-7.

Zhang, W. M. (2016). Running a responsible school: Take Hengshui High School as an example. Modern Education, 18(13), 25-26.

Zheng, R. (2005). Discussion about educational function of the College Entrance Examination. Journal of Educational Development, 23(1), 4-6.

Zheng, R. (2007a). The rationality of the national College Entrance Examination: Analysis on basic social functions and influences of the College Entrance Examination. Journal of Higher Education, 28(6), 33-37.

Zheng, R. (2007b). Social function of the College Entrance Examination. Modern University Education, 23(3), 31-34. 
Zheng, R., \& Wan, Y. (2015). The problem of unified College Entrance Examination and evaluation of its causes. Journal of Central China Normal University (Humanities and Social Sciences), 54(4), 154-160.

Zhou, B. (2009). Discussion about the lack and promotion of educational function in the College Entrance Examination system. Theory and Practice of Education, 29(1), 17-21.

Zhu, Y. (2004). The division system of liberal arts and science, the cancer in Chinese education. Educational Science Research, 15(11), 61. 